\title{
Type II transglutaminase stimulates epidermal cancer stem cell epithelial-mesenchymal transition
}

\author{
Matthew L. Fisher ${ }^{1}$, Gautam Adhikary ${ }^{1}$, Wen Xu${ }^{1}$, Candace Kerr ${ }^{1}$, Jeffrey W. Keillor ${ }^{5}$, \\ Richard L. Eckert ${ }^{1,2,3,4}$ \\ ${ }^{1}$ Departments of Biochemistry and Molecular Biology, University of Maryland School of Medicine, Baltimore, Maryland, USA \\ ${ }^{2}$ Dermatology, University of Maryland School of Medicine, Baltimore, Maryland, USA \\ ${ }^{3}$ Reproductive Biology, University of Maryland School of Medicine, Baltimore, Maryland, USA \\ ${ }^{4}$ Marlene and Stewart Greenebaum Cancer, University of Maryland School of Medicine, Baltimore, Maryland, USA \\ ${ }^{5}$ Department of Chemistry, University of Ottawa, Ottawa, Ontario, Canada \\ Correspondence to: \\ Richard L. Eckert, e-mail: reckert@umaryland.edu \\ Keywords: epidermal squamous cell carcinoma, type II transglutaminase, cancer stem cell, TG2, epithelial mesenchymal transition \\ Received: January 23, 2015 \\ Accepted: April 25, 2015 \\ Published: May 08, 2015
}

\section{ABSTRACT}

Type II transglutaminase (TG2) is a multifunctional protein that has recently been implicated as having a role in ECS cell survival. In the present study we investigate the role of TG2 in regulating epithelial mesenchymal transition (EMT) in ECS cells. Our studies show that TG2 knockdown or treatment with TG2 inhibitor, results in a reduced EMT marker expression, and reduced cell migration and invasion. TG2 has several activities, but the most prominent are its transamidase and GTP binding activity. Analysis of a series of TG2 mutants reveals that TG2 GTP binding activity, but not the transamidase activity, is required for expression of EMT markers (Twist, Snail, Slug, vimentin, fibronectin, $\mathrm{N}$-cadherin and HIF-1a), and increased ECS cell invasion and migration. This coupled with reduced expression of E-cadherin. Additional studies indicate that NFKB signaling, which has been implicated as mediating TG2 impact on EMT in breast cancer cells, is not involved in TG2 regulation of EMT in skin cancer. These studies suggest that TG2 is required for maintenance of ECS cell EMT, invasion and migration, and suggests that inhibiting TG2 GTP binding/G-protein related activity may reduce skin cancer tumor survival.

\section{INTRODUCTION}

Epidermal squamous cell carcinoma (SCC) is among the most common cancers and the frequency is increasing at a rapid rate $[1,2]$. SCC is treated by surgical excision, but the rate of recurrence approaches $10 \%$ and the recurrent tumors are aggressive and difficult to treat [2]. We propose that human epidermal cancer stem (ECS) cells survive at the site of tumor excision, that these cells give rise to tumor regrowth, and that therapies targeted to kill ECS cells constitute a viable anti-cancer strategy. An important goal in this context is identifying and inhibiting activity of key proteins that are essential for ECS cell survival. Working towards this goal, we have developed systems for propagation of human ECS cells [3]. These cells display properties of cancer stem cells including self-renew and high level expression of stem cell marker proteins [3].

In the present study we demonstrate that ECS cells express proteins characteristic of cells undergoing EMT (epithelial-mesenchymal transition). EMT is a morphogenetic process whereby epithelial cells lose epithelial properties and assume mesenchymal characteristics [4]. The epithelial cells lose cell-cell contact and polarity, and assume a mesenchymal migratory phenotype. There are three types of EMT. This first is an embryonic process, during gastrulation, when the epithelial sheet gives rise to the mesoderm [5]. The second is a growth factor and cytokine-stimulated EMT that occurs at sites of tissue injury to facilitate wound repair [6]. The third is associated with epithelial cancer cell acquisition of a mesenchymal 
migratory/invasive phenotype. This process mimics normal EMT, but is not as well controlled and coordinated $[4,7,8]$. A number of transcription factors (ZEB1, ZEB2, snail, slug, and twist) that are expressed during EMT suppress expression of epithelial makers, including E-cadherin, desmoplakin and claudins [4]. Snail proteins also activate expression of vimentin, fibronectin and metalloproteinases [4]. Snail factors are not present in normal epithelial cells, but are present in the tumor cells and are prognostic factors for poor survival [4].

An important goal is identifying factors that provide overarching control of EMT in cancer stem cells. In this context, several recent papers implicate type II transglutaminase (TG2) as a regulator of EMT [9-12]. TG2, the best studied transglutaminase, was isolated in 1957 from guinea pig liver extract as an enzyme involved in the covalent crosslinks proteins via formation of isopeptide bonds [13]. However, subsequent studies reveal that TG2 also serves as a scaffolding protein, regulates cell adhesion, and modulates signal transduction as a GTP binding protein that participates in $G$ protein signaling [14]. TG2 is markedly overexpressed in cancer cells, is involved in cancer development [15-18], and has been implicated in maintaining and enhancing EMT in breast and ovarian cancer $[10,12,19,20]$. The $\mathrm{G}$ protein function may have an important role in these processes [10, 21-23].

In the present manuscript we study the role of TG2 in regulating EMT in human ECS cells. Our studies show that TG2 is highly enriched in ECS cells. We further show that these cells express EMT markers and that TG2 is required to maintain EMT protein expression. TG2 knockdown, or treatment with TG2 inhibitor, reduces EMT marker expression and ECS cell survival, invasion and migration. TG2 GTP binding activity is absolutely required for maintenance of EMT protein expression and EMT-related responses. However, in contrast to breast cancer $[9,10]$, we show that TG2 regulation of EMT is not mediated via $\mathrm{NF} \kappa \mathrm{B}$ signaling.

\section{RESULTS}

\section{TG2 is required for expression of EMT markers}

EMT is a property of tumor stem cells that confers an ability to migrate and invade surrounding tissue [24-26]. We first examined whether ECS cells express EMT markers. Non-stem cancer cells and ECS cells, derived from the SCC-13 cancer cell line, were analyzed for expression of EMT markers. Fig. 1A shows that a host of EMT transcriptional regulators, including Twist, Snail and Slug, are increased in ECS cells (spheroid) as compared to non-stem cancer cells (monolayer). This is associated with increased levels of vimentin, fibronectin and $\mathrm{N}$-cadherin, which are mesenchymal proteins, and reduced expression of E-cadherin, an epithelial marker. HIF-1 $\alpha$, an additional marker frequently associated with EMT, is also elevated.
We next examined whether TG2 is required to maintain EMT marker expression. SCC-13 cell-derived ECS cells were grown in the presence of control- or TG2-siRNA, to reduce TG2, and the impact on EMT marker level was measured. Fig. 1B shows that loss of TG2 is associated with reduced expression of Twist, Snail, vimentin and HIF-1 $\alpha$. To further assess the role of TG2, we utilized SCC13-Control-shRNA and SCC13-TG2-shRNA2 cell lines. These lines were produced by infection of SCC-13 cells with lentiviruses encoding control- or TG2-specific shRNA. Fig. 1C shows that SCC13-TG2-shRNA2 cells express markedly reduced levels of TG2 and that this is associated with reduced expression of EMT associated transcription factors and target proteins, and increased expression of E-cadherin. To confirm this, we grew SCC13-Control-shRNA and SCC13-TG2-shRNA2 cells as monolayer cultures for immunostain detection of EMT markers. As shown in Fig. 2A, TG2 levels are reduced in TG2-shRNA expressing cells, and this is associated with the anticipated changes in epithelial and mesenchymal marker expression.

Tumor cells that express EMT markers display enhanced migration and invasion ability [24-26]. We therefore examined the impact of TG2 reduction on these responses. To measure invasion, control-shRNA and TG2-shRNA cells were monitored for ability to move through matrigel. Fig. 2B shows that loss of TG2 reduces movement through matrigel by $50 \%$. We further show that this is associated with a reduction in cell migration using a monolayer culture wound closure assay. The control cells close the wound completely within $14 \mathrm{~h}$, while TG2 knockdown reduces closure rate (Fig. 2C).

\section{TG2 inhibitor reduces EMT marker expression and EMT functional responses}

NC9 is a recently developed TG2-specific inhibitor $[27,28]$. We therefore asked whether pharmacologic inhibition of TG2 suppresses EMT. SCC-13 cells were treated with 0 or $20 \mu \mathrm{M} \mathrm{NC9}$. Fig. 3A shows that NC9 treatment reduces EMT transcription factor (Twist, Snail, Slug) and EMT marker (vimentin, fibronectin, N-cadherin, HIF-1 $\alpha$ ) levels. Consistent with these changes, the level of the epithelial marker, E-cadherin, is elevated. Fig. 3B and $3 \mathrm{C}$ show that pharmacologic inhibition of TG2 activity also reduces EMT biological response. Invasion (Fig. 3B) and cell migration (Fig. 3C) are also reduced.

\section{Identification of TG2 functional domain required for EMT}

We next performed studies to identify the functional domains and activities required for TG2 regulation of EMT. TG2 is a multifunctional enzyme that serves as a scaffolding protein, as a transamidase, as a kinase, and as a GTP binding protein [21]. The two best studied 

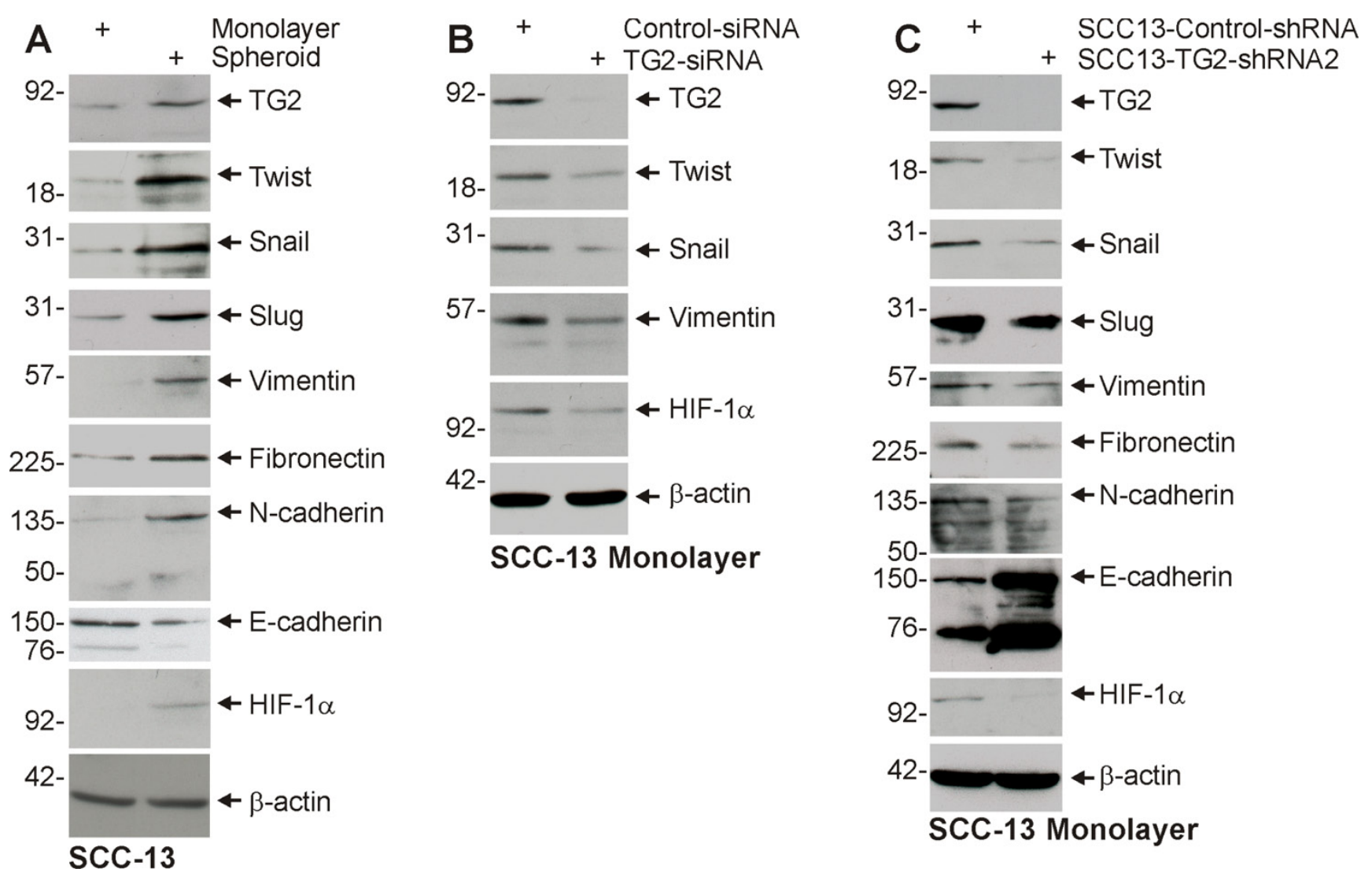

Figure 1: TG2 and EMT marker expression is enriched in ECS cells, and TG2 is required for EMT. A. ECS cells have elevated TG2 and mesenchymal markers. SCC-13 cells (40,000 per well) were grown in spheroid medium in attached (monolayer) and non-attached (spheroid, ECS cells). Cells were harvested after $10 \mathrm{~d}$ and lysates were prepared for electrophoresis and detection of the indicated epitopes. B. SCC-13 cells were electroporated with control- or TG2-siRNA and cultured in spheroid medium as monolayer cultures. After $72 \mathrm{~h}$ extracts were prepared to assay TG2 and EMT markers. C. SCC13-Control-shRNA and SCC13-TG2-shRNA2 cells were grown in spheroid media for $10 \mathrm{~d}$, harvested and lysates prepared for immune-detection of TG2 and EMT markers. Similar results were observed in three separate experiments.

functions are the transamidase and GTP binding/ G-protein related activities [21]. Transamidase activity is observed in the presence of elevated intracellular calcium, while GTP binding-related signaling is favored by low calcium conditions (reviewed in [21]). To identify the TG2 activity required for EMT, we measured the ability of wild-type and mutant TG2 to restore EMT in SCC13TG2-shRNA2 cells, which have reduced TG2 expression (Fig. 4A). SCC13-TG2-shRNA2 cells display reduced expression of EMT markers including Twist, Snail, Slug, vimentin, fibronectin, N-cadherin and HIF-1 $\alpha$, and increased expression of the epithelial maker, E-cadherin, as compared to SCC13-Control-shRNA cells. Expression of wild-type TG2, or the TG2-C277S or TG2-W241A mutants, restores marker expression in SCC13-TG2shRNA2 cells (Fig. 4A). TG2-C277S and TG2-W241A lack transamidase activity [10, 29-31]. In contrast, TG2R580A, which lacks G-protein activity [29-31], and TG2Y516F, which retains only partial G-protein activity [30], do not efficiently restore marker expression. These findings suggest that the TG2 GTP binding function is required for EMT.

We next assayed the ability of the TG2 mutants to restore EMT functional responses - invasion and migration. Fig. 4B and 4C shows that wild-type TG2, TG2C277S and TG2-W241A restore the ability of SCC13TG2-shRNA2 cells to invade matrigel, but TG2-R580A and $\mathrm{Y} 516 \mathrm{~F}$ are less active. Fig. 4D shows a similar finding for cell migration, in that the TG2-R580A and Y517F mutant are only partially able to restore SCC13-TG2shRNA2 cell migration. These findings suggest that TG2 GTP binding/G-protein related activity is required for EMT-related migration and invasion by skin cancer cells.

\section{Role of TG2 in regulating EMT in A431 cells}

The number of available epidermis-derived squamous cell carcinoma cell lines is limited, and so we 

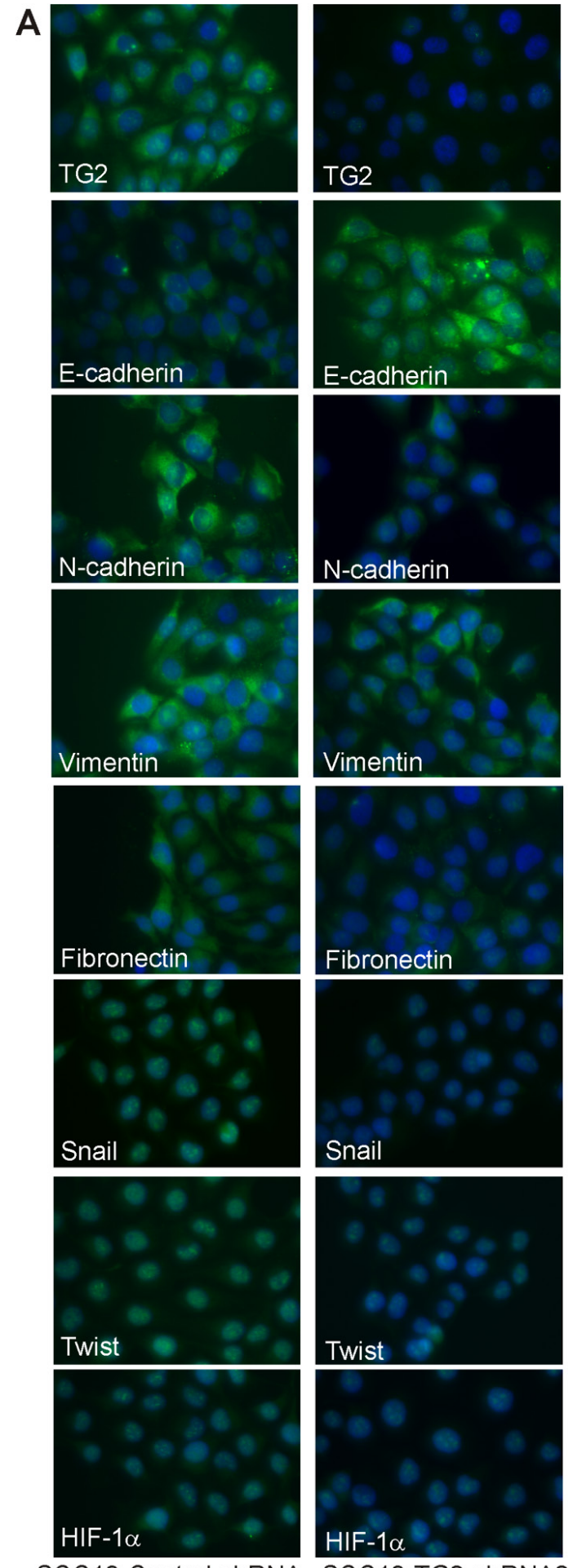

SCC13-Control-shRNA SCC13-TG2-shRNA2
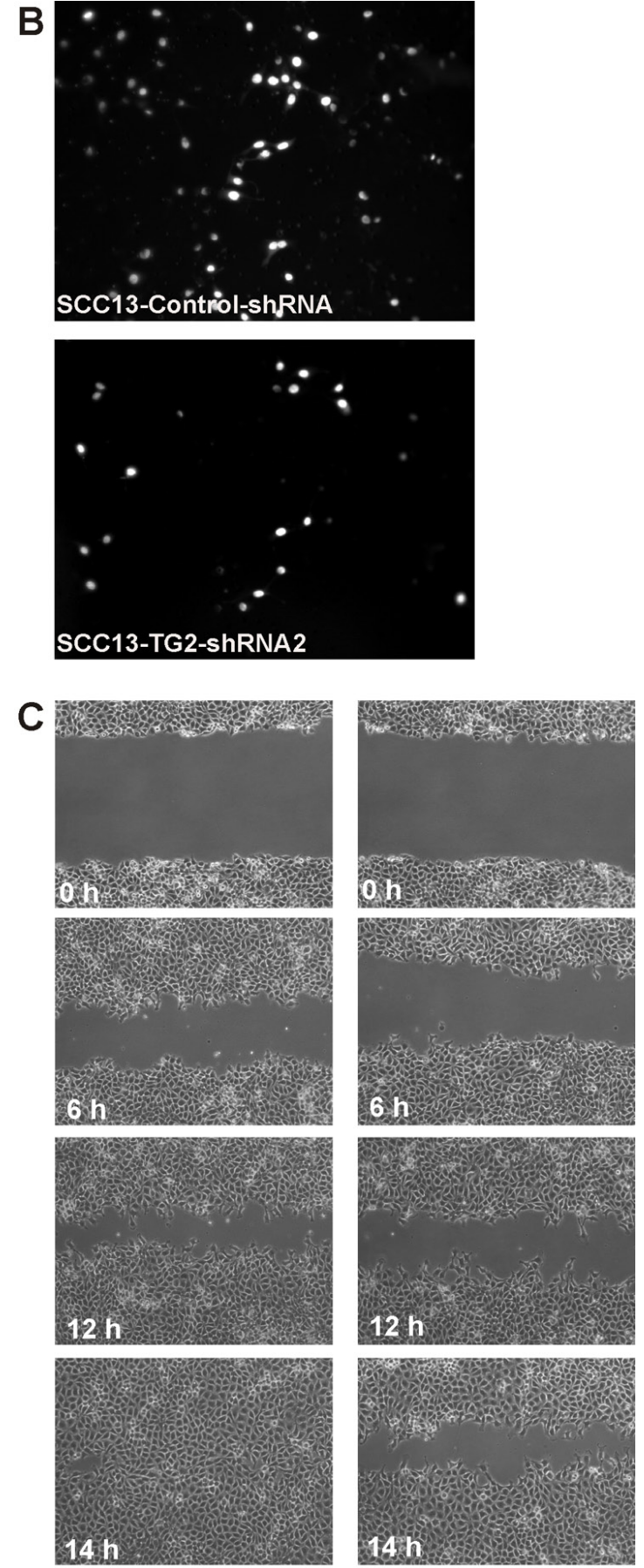

SCC13-Control-shRNA SCC13-TG2-shRNA2

Figure 2: TG2 is required for EMT marker expression and invasion/migration. A. SCC13-Control-shRNA and SCC13-TG2shRNA2 cells were grown in spheroid medium as spheroids in non-attached culture for $8 \mathrm{~d}$, and then plated as monolayers in 12 well plates (100,000 cells/well). After overnight attachment, the cells were fixed, permeabilized and incubated with antibodies specific for the indicated epitopes. B. SCC13-Control-shRNA and SCC13-TG2-shRNA2 cells were seeded on the upper chamber atop a matrigel-coated membrane in $1 \mathrm{ml}$ of growth medium in a Millicell chamber. After migration, the membrane was removed, rinsed, fixed and DAPI stained. Nuclei were counted on the underside of the membrane using an inverted fluorescent microscope. C. SCC13-Control-shRNA and SCC13-TG2-shRNA2 cells ( 2 million) were plated on $100 \mathrm{~mm}$ dishes in spheroid medium in monolayer conditions. The confluent monolayers were scratched with a $10 \mu \mathrm{l}$ pipette tip to create a wound and the released cells were removed. Images were taken at $0-14 \mathrm{~h}$ after the initial scratch. Similar results were observed in three experiments. 

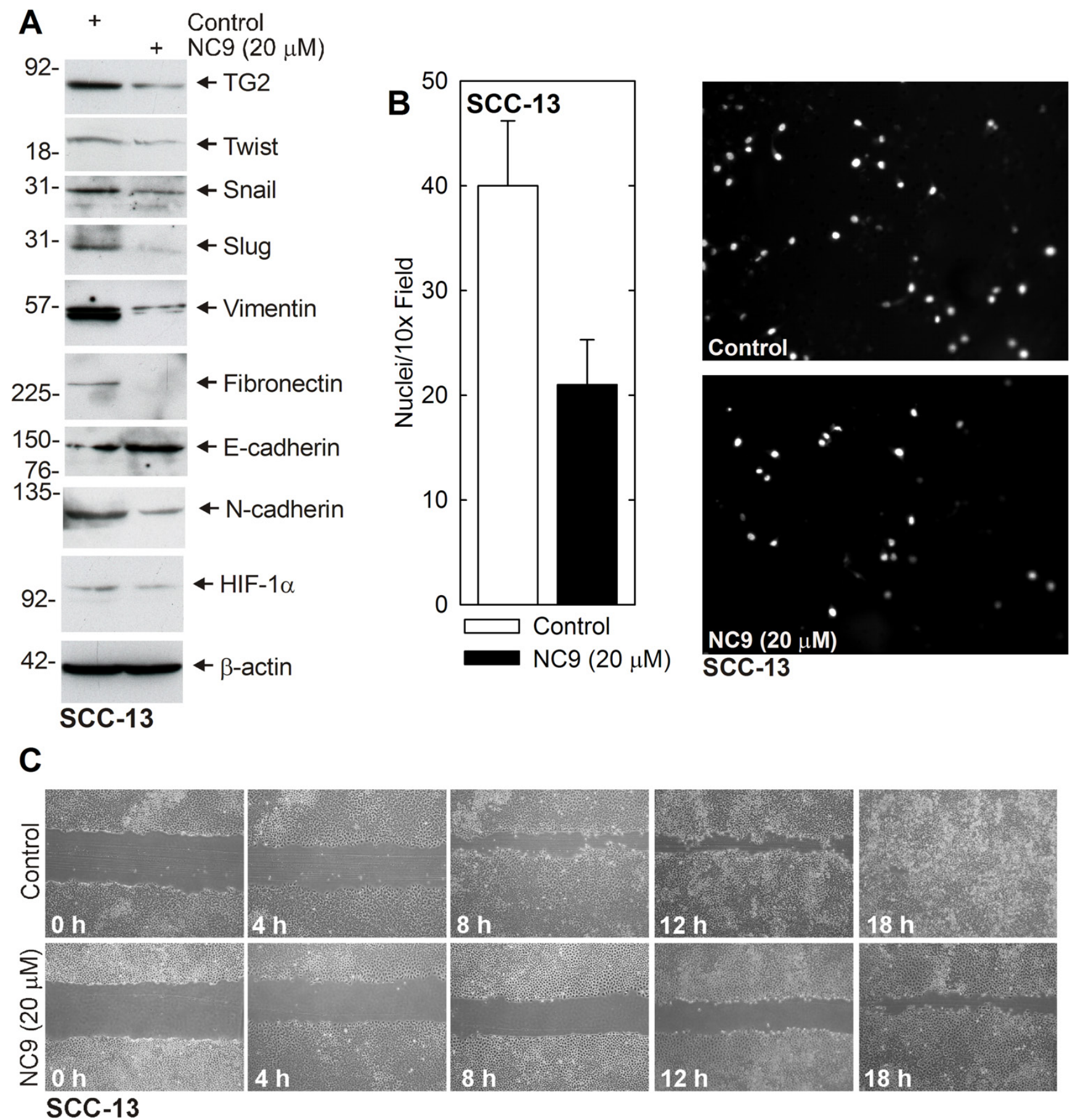

Figure 3: NC9 reduces EMT protein expression and invasion/migration. A. SCC-13 cells (500,000) were plated in monolayer culture in spheroid medium in $100 \mathrm{~mm}$ dishes. Fresh spheroid medium containing 0 or $20 \mu \mathrm{M}$ NC9 was added at time zero and again at $24 \mathrm{~h}$. After $48 \mathrm{~h}$ lysates were collected for electrophoresis and immunoblot. B. SCC-13 cells were pretreated with 0 or $20 \mu \mathrm{M}$ NC9 for $2 \mathrm{~h}$ and then harvested and plated (25,000 cells) in the upper chamber in $1 \mathrm{ml}$ of medium, above a matrigel-coated membrane, in a Millicell chamber. After $30 \mathrm{~h}$, the inside of membrane was harvested and the nuclei of migrated cells on the bottom of the membrane were counted using an inverted fluorescent microscope. The values are mean \pm SEM, $n=3(p, 0.05)$. C. SCC-13 (2 million) cells were plated in spheroid medium in $100 \mathrm{~mm}$ dishes and grown as monolayer cultures. Confluent monolayers were then scratched with a $10 \mu \mathrm{l}$ pipette tip and wound width was monitored for $0-18 \mathrm{~h}$. Similar results were observed in each of three experiments. 


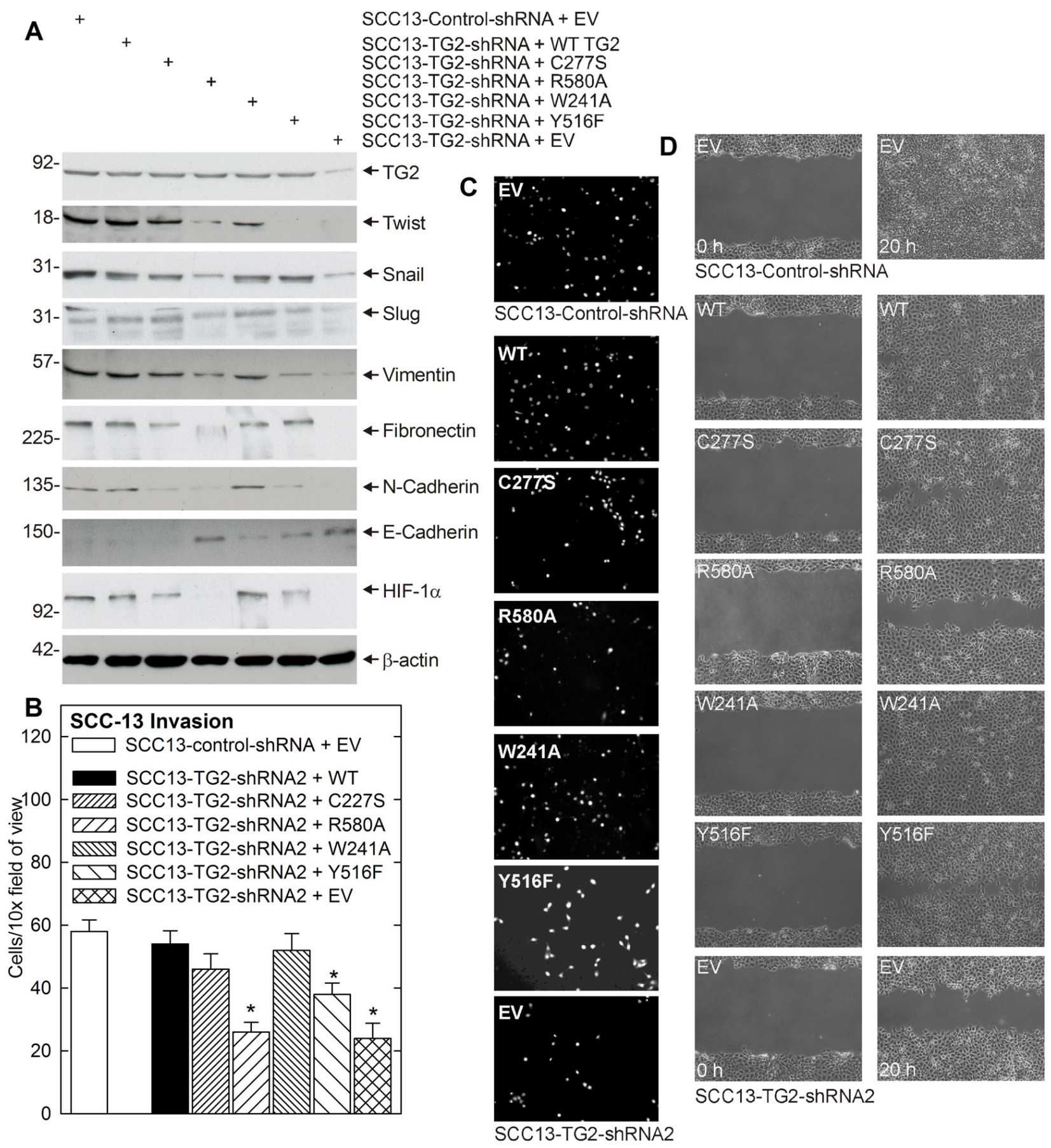

Figure 4: TG2 GTP binding/G-protein function is necessary for EMT. A. TG2 impact on EMT marker expression. SSC13Control-shRNA or SCC13-TG2-shRNA2 cells were electroporated with $3 \mu \mathrm{g}$ of empty vector (EV) or vector encoding the indicated TG2 proteins. The cells were then grown as monolayer cultures in spheroid medium for three days. The cells were then harvested and extracts prepared for electrophoresis and immunoblot detection of the indicated epitopes. Similar results were observed in three experiments. B. SCC13-TG2-shRNA2 cells were electroporated with plasmids encoding wild-type TG2, mutant TG2, or empty vector and grown in spheroid medium as monolayers. At $48 \mathrm{~h}$ post-electroporation, SCC13-Control-shRNA and SCC13-TG2-shRNA2 cells were harvested and seeded in the upper chamber above a matrigel-coated membrane in $1 \mathrm{ml}$ of spheroid medium containing $1 \%$ serum in a Millicell chamber. The lower chamber included spheroid medium containing $10 \%$ serum. Nuclei of migrated cells were stained and counted on the lower surface of the membrane using an inverted fluorescent microscope. The values are mean $\pm \mathrm{SEM}, n=3(p<0.01)$. C. Images of DAPIstained membrane. D. SCC13-Control-shRNA and SCC13-TG2-shRNA2 cells were electroporated with empty vector (EV) or vector encoding the indicated TG2 proteins and grown in spheroid medium as monolayers. After $24 \mathrm{~h}, 2$ million cells were plated in spheroid media on $100 \mathrm{~mm}$ dishes in monolayer conditions. The confluent monolayer cultures were then scratched with a $10 \mu \mathrm{l}$ pipette tip and width of the wound was monitored at $0-18 \mathrm{~h}$ to assess closure. Similar results were observed in each of three experiments. 
compared our findings with A431 cells. A431 cells are squamous cell carcinoma cells established from human vulvar skin. A431 cells were grown as monolayer (nonstem cancer cells) and spheroids (ECS cells) and after $10 \mathrm{~d}$ the cells were harvested and assayed for expression of TG2 and EMT makers. Fig. 5A shows that TG2 levels are elevated in ECS cells and that this is associated with increased levels of mesenchymal markers, including Twist, Snail, Slug, vimentin, fibronectin, N-cadherin and HIF-1 $\alpha$. In contrast, E-cadherin levels are reduced. We next examined the impact of TG2 knockdown on EMT marker expression. Fig. 5B shows that mesenchymal markers are globally reduced and E-cadherin level is increased. As a biological endpoint of EMT, we examine the impact of TG2 knockdown on spheroid formation and found that TG2 loss leads to reduced spheroid formation (Fig. 5C). We next examined the impact of $\mathrm{NC} 9$ treatment on EMT and found a reduction in EMT markers expression associated with an increase in epithelial (E-cadherin) marker level (Fig. 5D). This loss of EMT marker expression is associated with reduced matrigel invasion (Fig. 5E), reduced spheroid formation (Fig. 5F) and reduced cell migration (Fig. 5G).

\section{Role of NFKB}

Previous studies in breast [18, 32-36], ovarian cancer [12, 37, 38], and epidermoid carcinoma [11] indicate that $\mathrm{NF \kappa B}$ signaling mediates TG2 impact on EMT. We therefore assessed the role of $\mathrm{NF} \kappa \mathrm{B}$ in skin cancer cells. As shown in Fig. 6A, the increase in TG2 level observed in ECS cells (spheroids) is associated with reduced $\mathrm{NF} \kappa \mathrm{B}$ level. In addition, NF $\kappa \mathrm{B}$ level is increased in TG2 knockdown cells (Fig. 6B). Thus, increased NFкB is not associated with increased TG2. We next assessed the impact of NFאB knockdown on TG2 control of EMT marker expression. Fig. $6 \mathrm{C}$ shows that TG2 is required for increased expression of EMT markers (HIF-1 $\alpha$, snail, twist, N-cadherin, vimentin and fibronectin) and reduced expression of the E-cadherin epithelial marker; however, knockdown of NFאB expression does not interfere with TG2 regulation of these endpoints. We next examined the effect of TG2 knockdown on NF $\kappa B$ and $\mathrm{I} \kappa \mathrm{B} \alpha$ localization. The fluorescence images in Fig. 6D suggest that TG2 knockdown with TG2-siRNA does not alter the intracellular localization of $\mathrm{NF} \kappa \mathrm{B}$ or $\mathrm{I} \kappa \mathrm{B} \alpha$. This is confirmed by subcellular fractionation assay (Fig. 6E) which compares NFkB level in SCC13-TG2-Control and SCC13-TG2-shRNA2 (TG2 knockdown) cells. We also monitored NFkB subcellular distribution following treatment with NC9, the TG2 inhibitor. Fig. 6F shows that cytoplasmic/nuclear distribution of NFKB is not altered by NC9. Finally, we monitored the impact of TG2 expression

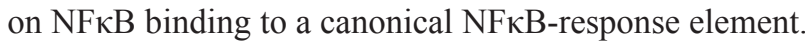
Increased $\mathrm{NF} \kappa \mathrm{B}$ binding to the response element is a direct measure of NFאB activity [10]. Fig. 6G shows that overall binding is reduced in nuclear $(\mathrm{N})$ extract prepared from ECS cells (spheroids) as compared to non-stem cancer cells (monolayer), and that NFkB binding, as indicated by gel supershift assay, is also slightly reduced in ECS cell extracts. These findings indicate that NFkB binding is slightly reduced in ECS cells, which are TG2-enriched (Fig. 1A).

We next monitored the role of $\mathrm{NF} \kappa \mathrm{B}$ on biological endpoints of EMT. Fig. 7A and 7B show that TG2 knockdown reduces migration through matrigel, but $\mathrm{NF \kappa B}$ knockdown has no impact. Likewise, TG2 knockdown reduces wound closure, but $\mathrm{NF} \kappa \mathrm{B}$ knockdown does not. These findings suggest that NFKB does not mediate the pro-EMT actions of TG2 in epidermal squamous cell carcinoma.

\section{DISCUSSION}

The metastatic cascade, from primary tumor to metastasis, is a complex process involving multiple pathways and signaling cascades [39-41]. Cells that complete the metastatic cascade migrate away from the primary tumor through the blood to a distant site and there form a secondary tumor. Identifying the mechanisms that allow cells to survive this journey and form secondary tumors is an important goal. The processes involved in epithelial-mesenchymal transition (EMT) are important cancer therapy targets, as EMT is associated with enhanced cancer cell migration and stem cell selfrenewal. EMT regulators, including Snail, Twist, Slug, are increased in expression in EMT and control expression of genes associated with the EMT phenotype [42].

\section{TG2 is required for EMT}

We have characterized a population of ECS cells derived from epidermal squamous cell carcinoma [3]. The present studies show that these cells, which display enhanced migration and invasion, possess elevated levels of TG2. Moreover, these cells are enriched in expression of transcription factors associated with EMT (Snail, Slug, and Twist, HIF-1 $\alpha$ ) as well as mesenchymal structural proteins including vimentin, fibronectin and $\mathrm{N}$-cadherin. Consistent with a shift to mesenchymal phenotype, E-cadherin, an epithelial marker, is reduced in level. Additional studies show that TG2 knockdown results in a marked reduction in EMT marker expression and that this is associated with reduced ability of the cells to migrate to close a scratch wound and reduced movement in matrigel invasion assays. We also examined the impact of treatment with a TG2 inhibitor. NC9 is an irreversible active site inhibitor of TG2, that locks the enzyme in an open conformation [28, 43-45]. NC9 treatment of ECS cells results in decreased levels of Snail, Slug and Twist. 

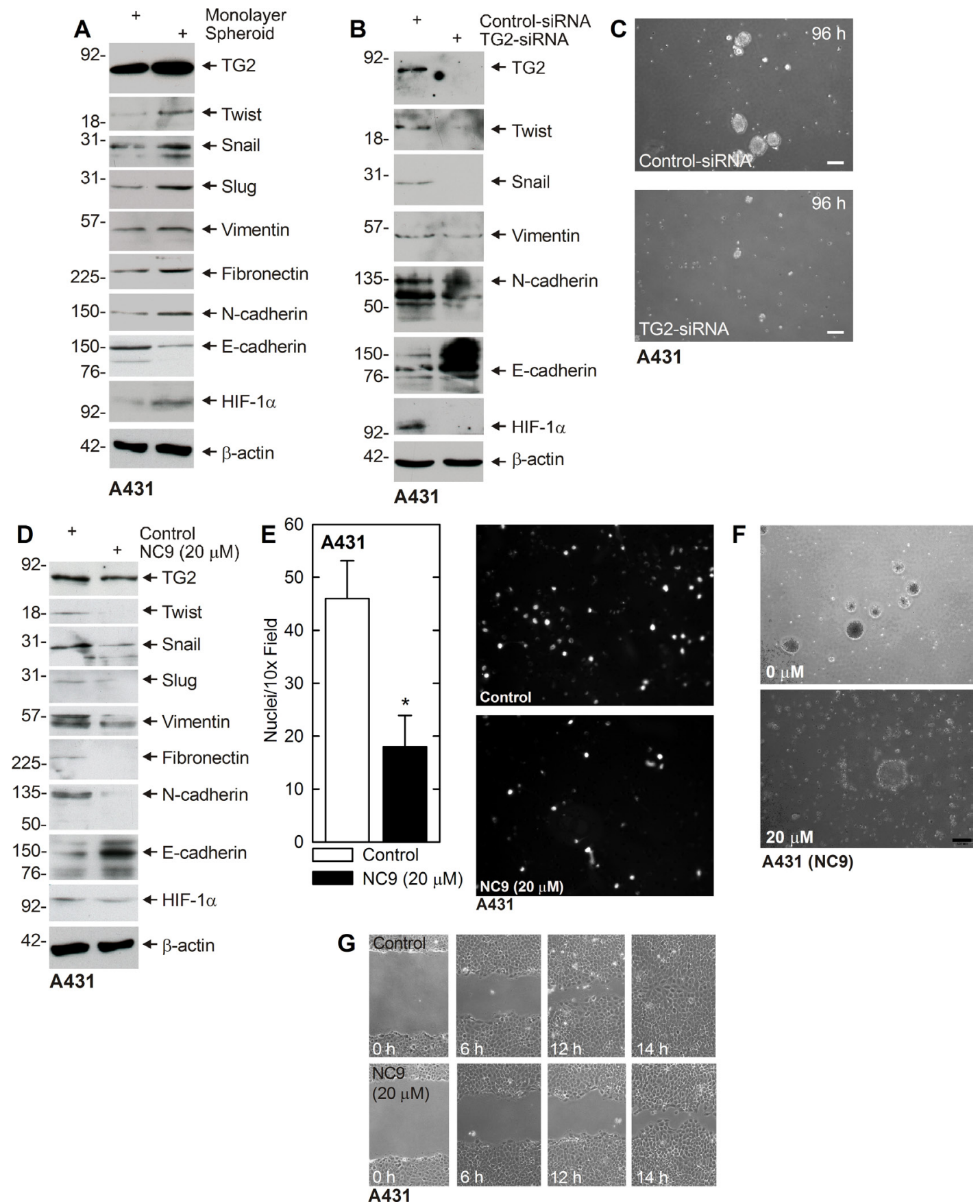

A431 (NC9)

Figure 5: TG2, EMT markers and EMT response in A431 cells. A. A431-derived ECS cells have elevated TG2 and mesenchymal markers. A431 cells (40,000 cells/well) were grown in spheroid media in monolayer conditions or as non-attached spheroids (ECS cells) for $10 \mathrm{~d}$. Cells were harvested and lysates prepared for immunoblot. B. A431 cells were electroporated with $3 \mu \mathrm{g}$ of control- or TG2siRNA and at $72 \mathrm{~h}$ extracts were prepared to assay TG2 and EMT marker level. C. A431-derived ECS cells were electroporated with $3 \mu \mathrm{g}$ of the indicated siRNA and then grown as spheroids for $96 \mathrm{~h}$. Similar results were observed in three separate experiments. D. A431 cells $(500,000$ cells/well $)$ were plated in monolayer culture in spheroid media in $100 \mathrm{~mm}$ dishes. The following day, at time zero, 0 or $20 \mu \mathrm{M}$ NC9 was added with fresh addition of medim and NC9 at $24 \mathrm{~h}$. At $48 \mathrm{~h}$ the cells were harvested and extracts prepared for immunoblot. E. A431 cells were pretreated in 0 or $20 \mu \mathrm{M}$ NC9 for $2 \mathrm{~h}$ and then harvested and 25,000 cells were seeded in the upper chamber above a matrigelcoated membrane in $1 \mathrm{ml}$ of growth medium containing 1\% FCS in a Millicell chamber. The lower chamber was filled with growth medium containing 10\% FCS. After $30 \mathrm{~h}$, the membrane was removed, washed and stained with DAPI, and an inverted fluorescent microscope was used to count the nuclei of migrated cells. F. A431 $(40,000)$ cells were plated in spheroid media in non-attached conditions. On d 8 , spheroids were treated with 0 or $20 \mu \mathrm{M} \mathrm{NC} 9$ and images were taken after $48 \mathrm{~h}$ to monitor spheroid fragmentation. G. A431 (2 million) cells were plated in spheroid media on $100 \mathrm{~mm}$ dishes and grown as monolayers. Confluent monolayers were then scratched with a $10 \mu \mathrm{l}$ pipette tip, rinsed, and width of the wound was monitored for 0-14 h. Similar results were observed in each of three experiments. 

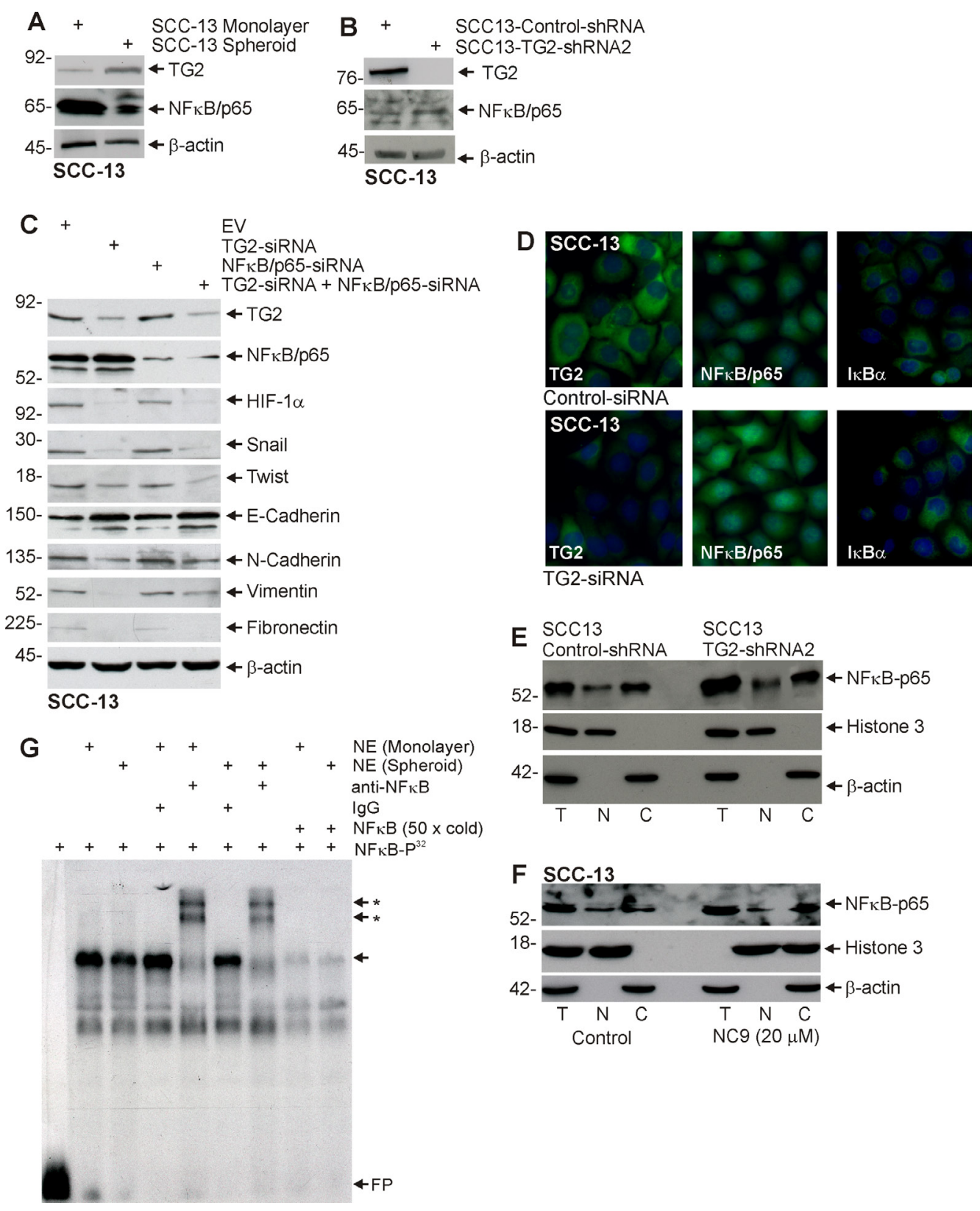

Figure 6: NFкB expression is not required for EMT. A. ECS cells have reduced NFkB-p65 levels. SCC-13 cells (40,000) were grown in spheroid medium in attached (monolayer) and non-attached (spheroid, ECS cells) conditions. Lysates were prepared after $10 \mathrm{~d}$ in culture for electrophoresis and detection of indicated epitopes. B. SCC13-Control-shRNA and SCC13-TG2-shRNA2 cells were grown in spheroid medium as monolayers. After $10 \mathrm{~d}$ in culture, lysates were collected for detection of TG2 and NFkB-p65. C. SCC-13 cells were electroporated with control-, NFKB-p65- or TG2-siRNA and then cultured as monolayers in spheroid medium. After $72 \mathrm{~h}$ extracts were prepared to assay TG2, NFkB-p65 and EMT markers. D. SCC-13 cells were electroporated with empty vector Control- or TG2-siRNA and plated in monolayer culture. The following day cells were fixed, permeabilized and incubated with antibodies specific for the indicated epitopes. Similar results were observed in each of three experiments. E. An equal number of cell equivalents of total (T), nuclear $(\mathrm{N})$, and cytosolic (C) extract, prepared from SCC13-Control-shRNA and SCC13-TG2-shRNA2 (TG2 knockdown) cells, was electrophoresed for immunoblot detection of $\mathrm{NF \kappa B}$, histone 3 (nuclear marker) and $\beta$-actin (cytoplasmic marker). Similar results were observed in three separate experiments. F. Total $(\mathrm{T})$, nuclear $(\mathrm{N})$, and cytosolic $(\mathrm{C})$ extract was prepared from 8 day spheroids (ECS cells) treated with 0 or $20 \mu \mathrm{M} \mathrm{NC9}$ for $48 \mathrm{~h}$. An equal number of cell equivalents of total, nuclear and cytosol extract was electrophoresed for immunoblot detection with the indicated antibodies. Similar results were observed in three separate experiments. G. Nuclear extract (NE), prepared from non-stem cancer cells (monolayer) or ECS cells (spheroids), was incubated with ${ }^{32} \mathrm{P}-\mathrm{NF}$ B probe and electrophoresed on a non-denaturing $6 \%$ acrylamide gel. Various groups were incubated with IgG, anti-NFkB or a 50 -fold $(50 \times$ cold $)$ molar excess of radioinert NFkB probe prior to electrophoresis. FP indicates free ${ }^{32} \mathrm{P}-\mathrm{NF} \kappa \mathrm{B}$ probe, the arrow indicates the gel mobility shift and the arrows with asterisks indicate the anti-dependent supershifted bands. 


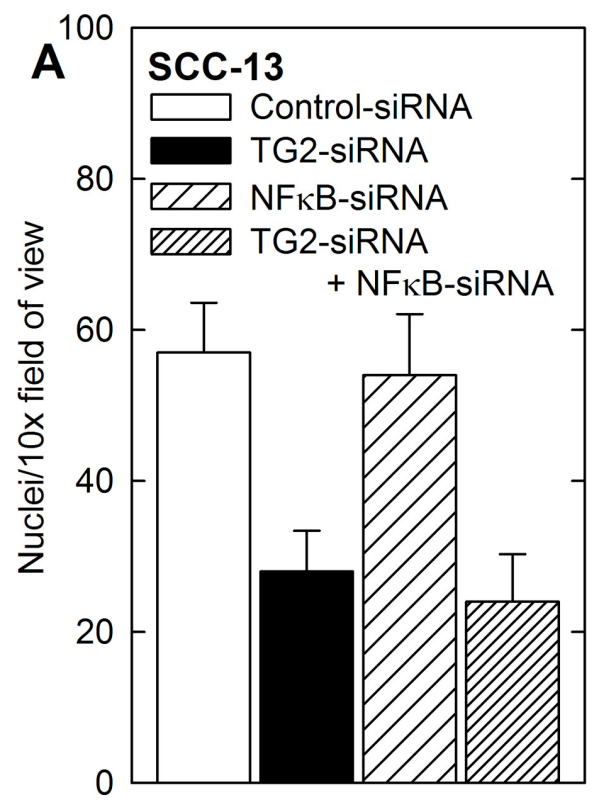

B
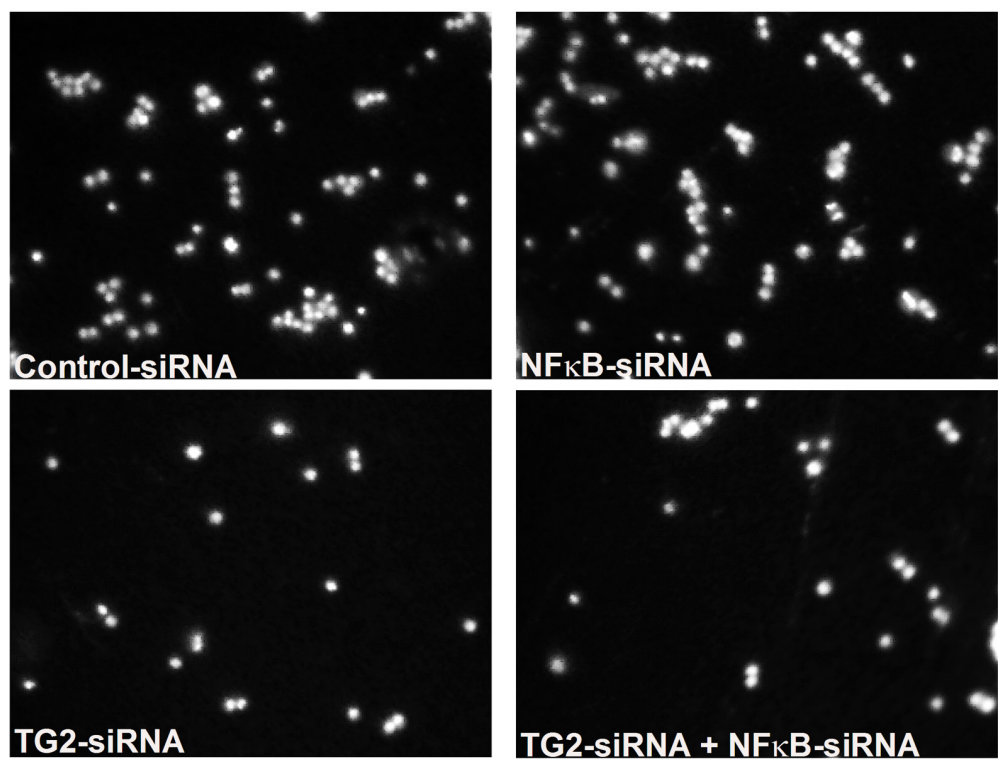

SCC-13
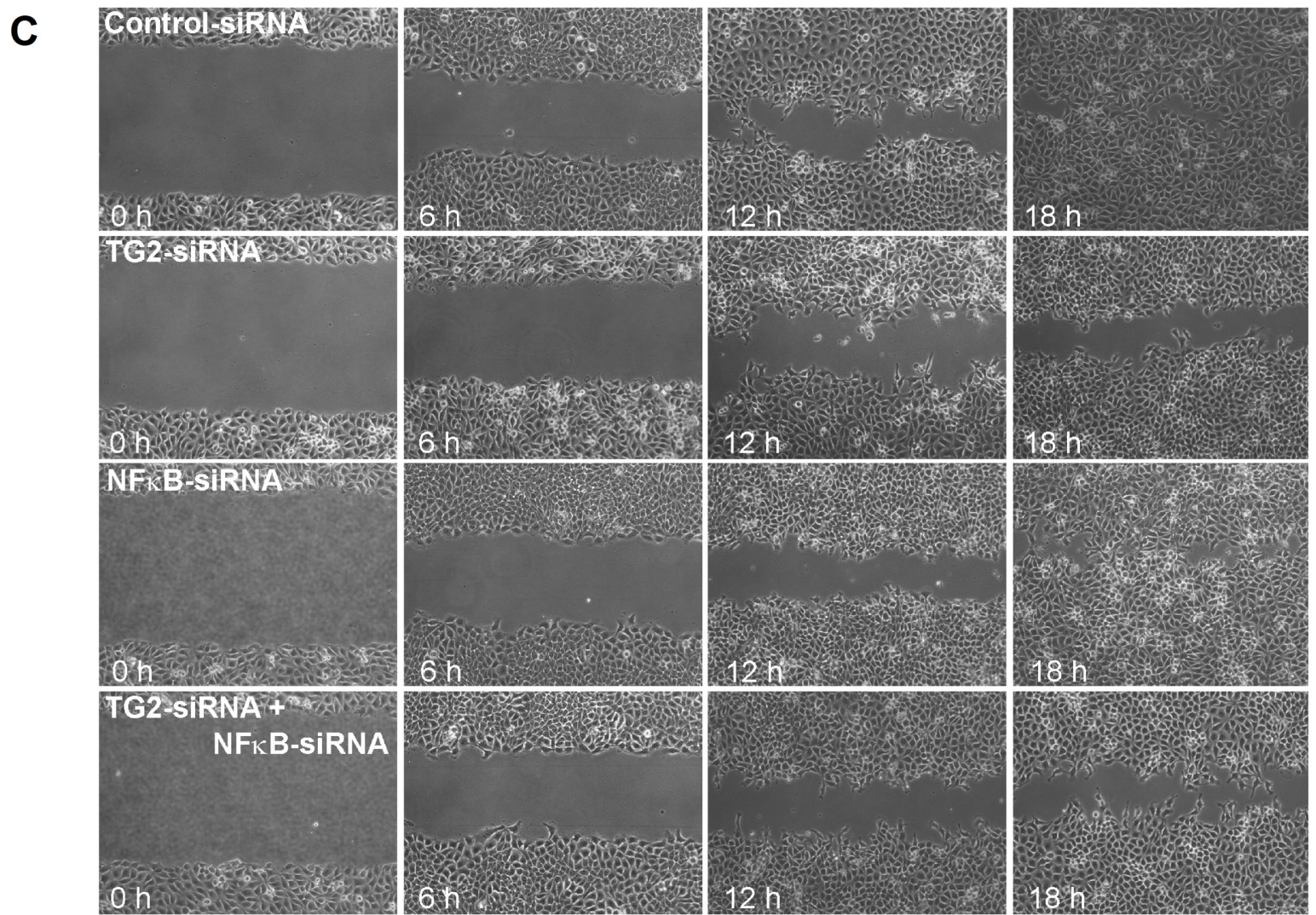

SCC -13

Figure 7: NFкB is not required for ECS cell migration and invasion. A, B. NFkB-knockdown does not suppress ECS cell matrigel invasion. SCC-13 cells were treated with Control-, TG2-, NFkB- or a combination of siRNA and then seeded in the upper chamber above a matrigel-coated membrane in $1 \mathrm{ml}$ of growth medium containing 1\% FCS in a Millicell chamber. The lower chamber was filled with growth medium containing 10\% FCS. After $30 \mathrm{~h}$, the membrane was removed, washed and stained with DAPI, and an inverted fluorescent microscope was used to count the nuclei of migrated cells. C. NFkB-knockdown does not impede ECS cell migration. SCC13 cells $(2$ million) cells were plated in spheroid media on $100 \mathrm{~mm}$ dishes and grown as monolayers. Confluent monolayers were then scratched with a $10 \mu \mathrm{l}$ pipette tip, rinsed, and width of the wound was monitored for $0-18 \mathrm{~h}$. Similar results were observed in each of three experiments. 
These transcription factors suppress E-cadherin expression [46] and their decline in level is associated with increased levels of E-cadherin. NC9 inhibition of TG2 also reduces expression of vimentin, fibronectin and $\mathrm{N}$-cadherin, and these changes are associated with reduced cell migration and reduced invasion through matrigel.

We also examined the role of TG2 in A431 squamous cell carcinoma cells derived from the vulva epithelium. TG2 is elevated in A431-derived ECS cells, as are EMT markers, and knockdown of TG2, with TG2siRNA, reduces EMT marker expression and spheroid formation. Studies with NC9 indicate that NC9 inhibits A431 spheroid formation, EMT, migration and invasion. These studies indicate that TG2 is also required for EMT and migration and invasion in A431 cells. Based on these findings we conclude that TG2 is essential for EMT, migration and invasion, and is likely to contribute to metastasis in squamous cell carcinoma.

\section{TG2 GTP binding activity is required for EMT}

TG2 is a multifunctional enzyme that can act as a transamidase, GTP binding protein, protein disulfide isomerase, protein kinase, protein scaffold, and DNA hydrolase [21, 29, 44, 47]. The two most studied functions are the transamidase and GTP binding functions $[29,44,47]$. To identify the TG2 activity responsible for induction of EMT, we studied the ability of TG2 mutants to restore EMT in SCC13-TG2-shRNA2 cells, which express low levels of TG2 and do not express elevated levels of EMT markers or display EMT-related biological responses. These studies show that wild-type TG2 restores EMT marker expression and the ability of the cells to migrate on plastic and invade matrigel. TG2 mutants that retain GTP binding activity (TG2-C277S and TG2-W241A) also restore EMT. In contrast, TG2-R580A, which lacks GTP binding function, does not restore EMT. This evidence suggests that the GTP binding function is essential for TG2 induction of the EMT phenotype in ECS cells. Recent reports suggest that the TG2 is important for maintenance of stem cell survival in breast $[9,10,17]$ and ovarian [12, 38, 48] cancer cells. Moreover, our findings are in agreement of those of Mehta and colleagues who reported that the TG2 GTP binding function, but not the crosslinking function, is required for TG2 induction of EMT in breast cancer cells [10].

\section{TG2, NFкB signaling and EMT}

To gain further insight into the mechanism of TG2 mediated EMT, we examined the role of NFkB. $\mathrm{NF} \kappa \mathrm{B}$ has been implicated as mediating EMT in breast, ovarian, and pancreatic cancer; however, NFкB may have a unique role in epidermal squamous cell carcinoma. In keratinocytes, NF $\kappa \mathrm{B}$ has been implicated in keratinocyte dysplasia and hyperproliferation [49]. However, inhibition of NFkB function has also been shown to predispose murine epidermis to cancer [50]. Here we show that TG2 levels are elevated and NFKB levels are reduced in ECS cells as compared to non-stem cancer cells, and that TG2 knockdown is associated with increased NFאB level. In addition, TG2 knockdown, or inhibition of TG2 by treatment with NC9, does not altered the nuclear/ cytoplasmic distribution of NFkB. We further show that elevated levels of TG2 in spheroid culture results in a slight reduction in $\mathrm{NF} \kappa \mathrm{B}$ binding to the $\mathrm{NF} \kappa \mathrm{B}$ response element, as measured by gel mobility supershift assay. These molecular assays strongly suggest that NFкB does not mediate the action of TG2 in epidermal cancer stem cells. Moreover, knockdown of NFאB-p65 in TG2 positive cells does not result in a reduction in Snail, Slug and Twist, or mesenchymal marker proteins expression, and concurrent knockdown of TG2 and NFkB does not reduce EMT marker protein levels beyond that of TG2 knockdown alone. These findings suggest that NFкB is not an intermediary in TG2-stimulated EMT in ECS cells. This is in contrast to the required role of NFKB in mediating TG2 induction of cell survival and EMT in breast cancer cells [18, 32, 33] and ovarian cancer $[12,37,38]$ and epidermoid carcinoma [11].

\section{MATERIALS AND METHODS}

\section{Reagents}

Cells were maintained as monolayer cultures in growth medium including DMEM (Invitrogen, Frederick, MD) supplemented with $4.5 \mathrm{mg} / \mathrm{ml} \mathrm{D-glucose,} 200 \mathrm{mM}$ L-glutamine, $100 \mathrm{mg} / \mathrm{ml}$ sodium pyruvate, and 5\% fetal calf serum. Heat-inactivated fetal calf serum (FCS, F4135) and anti- $\beta$-actin (A5441) were purchased from Sigma (St. Louis, Mo). Cell lysis Buffer (9803) was purchased from Cell Signaling Technology (Danvers, MA). AntiTG2 (2187378) was purchased from EMD Millipore

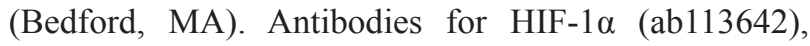
Twist (ab49254) and Slug (ab27568) were purchased from Abcam. Antibodies for vimentin (5741) and Snail (3895) were purchased from Cell Signaling Technologies. NFкB-p65 antibody (sc-109) was purchased from Santa Cruz (Santa Cruz, CA). Anti-E-cadherin was purchased from Epitomics (Ab40772). N-cadherin (610920) and fibronectin (610077) antibodies were purchased from BD Biosciences (San Jose, CA). Peroxidase-conjugated antimouse IgG (NXA931) and anti-rabbit IgG (NA934V) were obtained from GE Healthcare (Buckinghamshire, UK). Alexa Fluor 555 goat anti-mouse IgG (A21424) and Alexa Fluor 488 goat-anti-rabbit IgG (A11034) were purchased from Invitrogen. DAPI (D9542) was purchased from Sigma. NC9 synthesis was previously described [27, 28]. TG2- (sc-37514) and control-siRNA (sc-37007) were purchased from Santa Cruz (Dallas, TX). 
Matrigel (354234) and BD Biocoat cell inserts (353097) were purchased from BD Biosciences.

\section{Immunoblot}

Equivalent amounts of protein were electrophoresed on denaturing and reducing 10\% polyacrylamide gels and transferred to nitrocellulose membrane. The membrane was blocked by $5 \%$ nonfat dry milk for $1 \mathrm{~h}$ and incubated with primary antibody (diluted 1:1000) in 5\% nonfat dry milk. Blots were rinsed and then incubated with secondary antibody (diluted 1:5000) for $2 \mathrm{~h}$. Secondary antibody binding was visualized using ECL Prime chemiluminescence detection technology (Amersham).

\section{TG2-shRNA lentivirus production}

TG2-shRNA encoding lentivirus was produced using 293 T packaging cells maintained in Dulbecco's modified Eagle's medium containing $1 \mathrm{mM} \mathrm{L-glutamine,}$ $1 \mathrm{mM}$ sodium pyruvate and $10 \%$ fetal calf serum. Cells were plated in $100 \mathrm{~mm}$ dishes at $50 \%$ confluence $24 \mathrm{~h}$ prior to transfection. The media was removed, and the cells washed with Hank's Balanced Salt Solution and transferred to serum-free growth medium $24 \mathrm{~h}$ before prior to transfection with $1 \mu \mathrm{g}$ of pCMV-VSVG, $0.5 \mu \mathrm{g}$ pCMV-dr8.91 and $0.5 \mu \mathrm{g}$ TG2-shRNA encoding plasmid. pCMV-VSVG (8454) and pCMV-dr8.91 were purchased from Addgene and kindly provided by Dr. CY Lin. The lentivirus plasmids, pLKO.1-NT-Puro-shRNA (Control) (SHC016) and pLKO.1-Puro-hTGM2-shRNA (TRCN0000272760) were from Sigma-Aldrich (St. Louis, MO). At $3 \mathrm{~h}$ post-transfection, fresh medium containing $10 \%$ FCS was added. After an additional $72 \mathrm{~h}$ the conditionedmedium was collected, centrifuged for $15 \mathrm{~min}$ at 1,500 RPM, filtered through a $22 \mu \mathrm{m}$ filter and pipetted into aliquots for storage at $-80 \mathrm{C}$.

\section{Stable TG2 knockdown cell lines}

SCC-13 cells $\left(1 \times 10^{5}\right)$ were plated in 24 well cluster plates and allowed to attach overnight, followed by incubation with $1 \mathrm{ml}$ of pLKO.1-Puro-hTGM2shRNA lentivirus in serum-free growth media containing $8 \mu \mathrm{g} / \mathrm{ml}$ polybrene at $37 \mathrm{C}$ for $5 \mathrm{~h}$. The media was then supplemented with $5 \%$ fetal calf serum followed by selection for two weeks with $0.25 \mu \mathrm{g} / \mathrm{ml}$ puromycin. The resulting cells were infected a second time with the same virus and reselected with puromycin to produce the SCC13-TG2-shRNA2 cell line. TG2 knockdown was confirmed by anti-TG2 immunoblot. A control cell line, SCC13-Control-shRNA, was produced by double infection with pLKO.1-Puro-NT-shRNA lentivirus, which encodes control-shRNA, using an identical protocol.

\section{Spheroid formation assay}

Cells, maintained as monolayer cultures in growth medium consisting of DMEM (Invitrogen, Frederick, MD) supplemented with $4.5 \mathrm{mg} / \mathrm{ml}$ D-glucose, $200 \mathrm{mM}$ L-glutamine, $100 \mathrm{mg} / \mathrm{ml}$ sodium pyruvate, and $5 \%$ fetal calf serum, were harvested, collected by centrifugation, and resuspended in spheroid medium comprising DMEM/F12 (1:1) (DMT-10-090$\mathrm{CV}$, Mediatech INC, Manassa, VA) supplemented with 2\% B27 serum-free supplement (17504-044, Invitrogen, Frederick, MD), 20 ng/ml EGF (E4269, Sigma, St. Louis), $0.4 \%$ bovine serum albumin (B4287, Sigma) and $4 \mu \mathrm{g} / \mathrm{ml}$ insulin (19278 Sigma, St. Louis, MO.). The cells $(40,000)$ were plated in $9.6 \mathrm{~cm}^{2}$ wells in Costar six well ultra-low attachment cluster dishes (4371, Corning, Tewksbury, MA). Spheroid size and number was monitored with time in culture as previously described [3].

\section{Electroporation of nucleic acids}

Cells were maintained in monolayer culture in growth medium. Near-confluent cultures were harvested the day prior to electroporation and plated in $60 \mathrm{~mm}$ dishes in growth medium. After $24 \mathrm{~h}$, when 50\% confluent, the cells were re-trypsinized, centrifuged at $200 \times \mathrm{g}$, and replated. The next morning $1 \times 10^{6}$ cells were harvested, washed with sterile phosphate-buffered saline, suspended in $100 \mu \mathrm{l}$ of keratinocyte nucleofection reagent containing $3 \mu \mathrm{g}$ of plasmid or siRNA and electroporated using the Amaxa Electroporator on the T-018 setting [51]. Immediately after electroporation, the cells were resuspended in pre-warmed medium and plated. When siRNA was used, the cells were harvested at $72 \mathrm{~h}$ post-electroporation and re-electroporated a second time. This double electroporation assured sustained target knockdown.

\section{Invasion assay}

Matrigel was diluted in $0.01 \mathrm{M}$ Tris- $\mathrm{HCl} / 0.7 \%$ $\mathrm{NaCl}$, filter sterilized and $0.1 \mathrm{ml}$ was used to coat individual BD BioCoat inserts (Millicell-PCF, $0.4 \mu \mathrm{m}$, $12 \mathrm{~mm}$, PIHP01250). Cells $(25,000)$ were plated in $100 \mu \mathrm{l}$ in growth medium, supplemented with $1 \%$ FCS, in the upper chamber. The lower chamber contained growth medium supplemented with $10 \%$ FCS. After migration, the membranes were harvested and excess cells were removed from the upper membrane surface. The membrane was fixed in $4 \%$ paraformaldehyde, stained with $1 \mu \mathrm{g} / \mathrm{ml}$ DAPI, and the underside of the membrane was photographed with an inverted fluorescent microscope and the number of cells counted. 


\section{Migration assay}

SCC13-Control-shRNA or SCC13-TG2-shRNA2 cells $\left(2 \times 10^{6}\right)$ were plated in $10 \mathrm{~cm}$ dishes and grown as monolayer cultures in spheroid medium until confluent. A $10 \mu$ pipette tip was used to prepare areas void of cells and the dishes were washed to remove the dislodged cells. Images were collected, at $0-18 \mathrm{~h}$ after the scratch using the $10 \times$ objective, and the width of the opening was measured as a function of time as an index of cell migration potential.

\section{Gel mobility shift assay}

For gel mobility shift assay, $3 \mu \mathrm{g}$ of nuclear extract was incubated for $30 \mathrm{~min}$ at room temperature in a $20 \mu \mathrm{l}$ volume containing $20 \mathrm{mM}$ HEPES, pH 7.5, 10\% glycerol, $50 \mathrm{mM}$ $\mathrm{KCl}, 2 \mathrm{mM} \mathrm{MgCl}, 0.5 \mathrm{mM}$ EDTA, $0.5 \mathrm{mM}$ DTT, $1 \mathrm{mg} / \mathrm{ml}$ poly(dI:dC), $0.1 \mathrm{mg} / \mathrm{ml}$ bovine serum albumin, and 40,000 cpm radioactive double-stranded ${ }^{32} \mathrm{P}-\mathrm{NF} \kappa \mathrm{B}$ binding site oligonucleotide (5'-AGTTGAGGGGACTTTCCCAGGC). For competition studies, a 50-fold molar excess of nonradioactive competitor $\mathrm{NF} \kappa \mathrm{B}$ oligonucleotide was added to the DNA binding reaction. For gel mobility supershift assay, $2 \mu \mathrm{g}$ of normal rabbit IgG (sc-3888) or rabbit anti-NFkB (sc-109), purchased from Santa Cruz Biotechnology, was added to the reaction mixture and incubated $1 \mathrm{~h}$ at $25 \mathrm{C}$. The ${ }^{32} \mathrm{P}$-labeled probe was then added and the incubation was continued for an additional $30 \mathrm{~min}$ at $25 \mathrm{C}$. ProteinDNA complexes were resolved by electrophoresis on a $6 \%$ polyacrylamide nondenaturing gel [52].

\section{Cell fractionation}

Cell fractionation was performed using the NE-PER Nuclear and Cytoplasmic Extraction Kit (78440) and Halt protease inhibitor (78440) obtained from Thermo-Scientific (Waltham, MA). Four million cells were trypsinized, washed in phosphate-buffered saline and pelleted. The pellet was resuspended in $200 \mu \mathrm{l}$ of ice cold CER I buffer and maintained for 10 min on ice. Ice-cold CER II buffer $(50 \mu l)$ was added, the sample was vortexed and maintained on ice for $1 \mathrm{~min}$ prior to centrifugation. The supernatant (cytosol) was then collected as a total volume of $250 \mu \mathrm{l}$ and stored at $-80 \mathrm{C}$. The nuclear pellet was suspended, by repeated vortexing, in $50 \mu \mathrm{l}$ of ice cold NER buffer over $40 \mathrm{~min}$. The sample was then centrifuged for $10 \mathrm{~min}$ and the nuclear extract was stored at $-80 \mathrm{C}$ until use. For analysis, 0.56 million cell equivalents of nuclear $(35 \mu \mathrm{l})$ or cytosolic $(7 \mu \mathrm{l})$ extract was electrophoresed for immunoblot detection of $\mathrm{NF \kappa B}$, histone $\mathrm{H} 3$ and $\beta$-actin.

\section{ACKNOWLEDGMENTS}

This work was supported by grants from the Maryland Stem Cell Research Foundation (RLE, CK) and the National Institutes of Health (RLE - CA131074), and an American Cancer Society Institutional Research Grant provided through the University of Maryland Greenebaum Cancer Center (CK).

\section{REFERENCES}

1. Christenson LJ, Borrowman TA, Vachon CM, Tollefson MM, Otley CC, Weaver AL, Roenigk RK. Incidence of basal cell and squamous cell carcinomas in a population younger than 40 years. JAMA. 2005; 294:681-690.

2. Moller R, Reymann F, Hou-Jensen K. Metastases in dermatological patients with squamous cell carcinoma. Arch Dermatol. 1979; 115:703-705.

3. Adhikary G, Grun D, Kerr C, Balasubramanian S, Rorke EA, Vemuri M, Boucher S, Bickenbach JR, Hornyak T, Xu W, Fisher ML, Eckert RL. Identification of a population of epidermal squamous cell carcinoma cells with enhanced potential for tumor formation. PLoS One. 2013; 8:e84324.

4. Samatov TR, Tonevitsky AG, Schumacher U. Epithelialmesenchymal transition: focus on metastatic cascade, alternative splicing, non-coding RNAs and modulating compounds. Mol Cancer. 2013; 12:107.

5. Chaffer CL, Thompson EW, Williams ED. Mesenchymal to epithelial transition in development and disease. Cells Tissues Organs. 2007; 185:7-19.

6. Zeisberg EM, Tarnavski O, Zeisberg M, Dorfman AL, McMullen JR, Gustafsson E, Chandraker A, Yuan X, $\mathrm{Pu}$ WT, Roberts AB, Neilson EG, Sayegh MH, Izumo $\mathrm{S}$, et al. Endothelial-to-mesenchymal transition contributes to cardiac fibrosis. Nat Med. 2007; 13:952-961.

7. Thiery JP. Epithelial-mesenchymal transitions in tumour progression. Nat Rev Cancer. 2002; 2:442-454.

8. Lee JM, Dedhar S, Kalluri R, Thompson EW. The epithelial-mesenchymal transition: new insights in signaling, development, and disease. J Cell Biol. 2006; 172:973-981.

9. Kumar A, Xu J, Brady S, Gao H, Yu D, Reuben J, Mehta K. Tissue transglutaminase promotes drug resistance and invasion by inducing mesenchymal transition in mammary epithelial cells. PLoS One. 2010; 5:e13390.

10. Kumar A, Xu J, Sung B, Kumar S, Yu D, Aggarwal BB, Mehta K. Evidence that GTP-binding domain but not catalytic domain of transglutaminase 2 is essential for epithelial-to-mesenchymal transition in mammary epithelial cells. Breast Cancer Res. 2012; 14:R4. 
11. Lin CY, Tsai PH, Kandaswami CC, Chang GD, Cheng CH, Huang CJ, Lee PP, Hwang JJ, Lee MT. Role of tissue transglutaminase 2 in the acquisition of a mesenchymallike phenotype in highly invasive A431 tumor cells. Mol Cancer. 2011; 10:87.

12. Shao M, Cao L, Shen C, Satpathy M, Chelladurai B, Bigsby RM, Nakshatri H, Matei D. Epithelial-tomesenchymal transition and ovarian tumor progression induced by tissue transglutaminase. Cancer Res. 2009; 69:9192-9201.

13. Sarkar NK, Clarke DD, Waelsch H. An enzymically catalyzed incorporation of amines into proteins. Biochim Biophys Acta. 1957; 25:451-452.

14. Nakaoka H, Perez DM, Baek KJ, Das T, Husain A, Misono K, Im MJ, Graham RM. Gh: a GTP-binding protein with transglutaminase activity and receptor signaling function. Science. 1994; 264:1593-1596.

15. Pierce A, Whetton AD, Meyer S, Ravandi-Kashani F, Borthakur G, Coombes KR, Zhang N, Kornblau S. Transglutaminase 2 expression in acute myeloid leukemia: association with adhesion molecule expression and leukemic blast motility. Proteomics. 2013; 13:2216-2224.

16. Mangala LS, Fok JY, Zorrilla-Calancha IR, Verma A, Mehta K. Tissue transglutaminase expression promotes cell attachment, invasion and survival in breast cancer cells. Oncogene. 2007; 26:2459-2470.

17. Kumar A, Gao H, Xu J, Reuben J, Yu D, Mehta K. Evidence that aberrant expression of tissue transglutaminase promotes stem cell characteristics in mammary epithelial cells. PLoS One. 2011; 6:e20701.

18. Kumar S, Mehta K. Tissue transglutaminase, inflammation, and cancer: how intimate is the relationship? Amino Acids. 2013; 44:81-88.

19. Cao L, Shao M, Schilder J, Guise T, Mohammad KS, Matei D. Tissue transglutaminase links TGF-beta, epithelial to mesenchymal transition and a stem cell phenotype in ovarian cancer. Oncogene. 2012; 31:2521-2534.

20. Park MK, You HJ, Lee HJ, Kang JH, Oh SH, Kim SY, Lee $\mathrm{CH}$. Transglutaminase-2 induces $\mathrm{N}$-cadherin expression in TGF-beta1-induced epithelial mesenchymal transition via c-Jun-N-terminal kinase activation by protein phosphatase 2A down-regulation. Eur J Cancer. 2013; 49:1692-1705.

21. Eckert RL, Kaartinen MT, Nurminskaya M, Belkin AM, Colak G, Johnson GV, Mehta K. Transglutaminase regulation of cell function. Physiol Rev. 2014; 94:383-417.

22. Fesus L, Piacentini M. Transglutaminase 2: an enigmatic enzyme with diverse functions. Trends Biochem Sci. 2002; 27:534-539.

23. Ientile R, Caccamo D, Griffin M. Tissue transglutaminase and the stress response. Amino Acids. 2007; 33:385-394.

24. Kalluri R. EMT: when epithelial cells decide to become mesenchymal-like cells. J Clin Invest. 2009; 119:1417-1419.
25. Kalluri R, Weinberg RA. The basics of epithelialmesenchymal transition. J Clin Invest. 2009; 119:1420-1428.

26. Tam WL, Weinberg RA. The epigenetics of epithelial-mesenchymal plasticity in cancer. Nat Med. 2013; 19:1438-1449.

27. Keillor J, chica R, Chabot N, Vinci V, Pardin C, Fortin E, Gillet S, Nakano Y, Kaartinen M, Pelletier J, Lubell W. The bioorganic chemistry of transglutaminase - from mechanism to inhibition and engineering. Can J Chem. 2008; $86: 271-276$.

28. Caron NS, Munsie LN, Keillor JW, Truant R. Using FLIMFRET to measure conformational changes of transglutaminase type 2 in live cells. PLoS One. 2012; 7:e44159.

29. Gundemir S, Colak G, Tucholski J, Johnson GV. Transglutaminase 2: a molecular Swiss army knife. Biochim Biophys Acta. 2012; 1823:406-419.

30. Gundemir S, Johnson GV. Intracellular localization and conformational state of transglutaminase 2: implications for cell death. PLoS One. 2009; 4:e6123.

31. Gundemir S, Colak G, Feola J, Blouin R, Johnson GV. Transglutaminase 2 facilitates or ameliorates HIF signaling and ischemic cell death depending on its conformation and localization. Biochim Biophys Acta. 2013; 1833:1-10.

32. Agnihotri N, Kumar S, Mehta K. Tissue transglutaminase as a central mediator in inflammation-induced progression of breast cancer. Breast Cancer Res. 2013; 15:202.

33. Kumar S, Mehta K. Tissue Transglutaminase Constitutively Activates HIF-1alpha Promoter and Nuclear Factor-kappaB via a Non-Canonical Pathway. PLoS One. 2012; 7:e49321.

34. Kim DS, Han BG, Park KS, Lee BI, Kim SY, Bae CD. I-kappaBalpha depletion by transglutaminase 2 and mucalpain occurs in parallel with the ubiquitin-proteasome pathway. Biochem Biophys Res Commun. 2010; 399:300-306.

35. Kim JM, Voll RE, Ko C, Kim DS, Park KS, Kim SY. A new regulatory mechanism of NF-kappaB activation by I-kappaBbeta in cancer cells. J Mol Biol. 2008; 384:756-765.

36. Brown KD. Transglutaminase 2 and NF-kappaB: an odd couple that shapes breast cancer phenotype. Breast Cancer Res Treat. 2013; 137:329-336.

37. Cao L, Petrusca DN, Satpathy M, Nakshatri H, Petrache I, Matei D. Tissue transglutaminase protects epithelial ovarian cancer cells from cisplatin-induced apoptosis by promoting cell survival signaling. Carcinogenesis. 2008; 29:1893-1900.

38. Yakubov B, Chelladurai B, Schmitt J, Emerson R, Turchi JJ, Matei D. Extracellular tissue transglutaminase activates noncanonical NF-kappaB signaling and promotes metastasis in ovarian cancer. Neoplasia. 2013; 15:609-619. 
39. Micalizzi DS, Farabaugh SM, Ford HL. Epithelialmesenchymal transition in cancer: parallels between normal development and tumor progression. J Mammary Gland Biol Neoplasia. 2010; 15:117-134.

40. Thiery JP, Acloque H, Huang RY, Nieto MA. Epithelialmesenchymal transitions in development and disease. Cell. 2009; 139:871-890.

41. Voulgari A, Pintzas A. Epithelial-mesenchymal transition in cancer metastasis: mechanisms, markers and strategies to overcome drug resistance in the clinic. Biochim Biophys Acta. 2009; 1796:75-90.

42. Wang Y, Shi J, Chai K, Ying X, Zhou BP. The Role of Snail in EMT and Tumorigenesis. Curr Cancer Drug Targets. 2013; 13:963-972.

43. Al-Jallad HF, Myneni VD, Piercy-Kotb SA, Chabot N, Mulani A, Keillor JW, Kaartinen MT. Plasma membrane factor XIIIA transglutaminase activity regulates osteoblast matrix secretion and deposition by affecting microtubule dynamics. PLoS One. 2011; 6:e15893.

44. Colak G, Keillor JW, Johnson GV. Cytosolic guanine nucledotide binding deficient form of transglutaminase 2 (R580a) potentiates cell death in oxygen glucose deprivation. PLoS One. 2011; 6:e16665.

45. Clouthier CM, Mironov GG, Okhonin V, Berezovski MV, Keillor JW. Real-time monitoring of protein conformational dynamics in solution using kinetic capillary electrophoresis. Angew Chem Int Ed Engl. 2012; 51:12464-12468.
46. van RF, Berx G. The cell-cell adhesion molecule E-cadherin. Cell Mol Life Sci. 2008; 65:3756-3788.

47. Milakovic T, Tucholski J, McCoy E, Johnson GV. Intracellular localization and activity state of tissue transglutaminase differentially impacts cell death. J Biol Chem. 2004; 279:8715-8722.

48. Satpathy M, Cao L, Pincheira R, Emerson R, Bigsby R, Nakshatri H, Matei D. Enhanced peritoneal ovarian tumor dissemination by tissue transglutaminase. Cancer Res. 2007; 67:7194-7202.

49. Poligone B, Hayden MS, Chen L, Pentland AP, Jimi E, Ghosh S. A role for NF-kappaB activity in skin hyperplasia and the development of keratoacanthomata in mice. PLoS One. 2013; 8:e71887.

50. Dajee M, Lazarov M, Zhang JY, Cai T, Green CL, Russell AJ, Marinkovich MP, Tao S, Lin Q, Kubo Y, Khavari PA. NF-kappaB blockade and oncogenic Ras trigger invasive human epidermal neoplasia. Nature. 2003; 421:639-643.

51. Adhikary G, Chew YC, Reece EA, Eckert RL. PKC-delta and -eta, MEKK-1, MEK-6, MEK-3, and p38-delta Are Essential Mediators of the Response of Normal Human Epidermal Keratinocytes to Differentiating Agents. J Invest Dermatol. 2010.

52. Han B, Rorke EA, Adhikary G, Chew YC, Xu W, Eckert RL. Suppression of AP1 transcription factor function in keratinocyte suppresses differentiation. PLoS One. 2012; 7:e36941. 